\title{
Euratom success stories in facilitating pan-European education and training collaborative efforts
}

\author{
Roger Garbil* \\ European Commission (EC), DG Research and Innovation, Euratom, Brussels, Belgium
}

Received: 5 April 2019 / Accepted: 4 June 2019

\begin{abstract}
The European Atomic Energy Community (Euratom) Research and Training framework programmes are benefitting from a consistent success in pursuing excellence in research and facilitating Pan European collaborative efforts across a broad range of nuclear science and technologies, nuclear fission and radiation protection. To fulfil Euratom R\&D programmes key objectives of maintaining high levels of nuclear knowledge and building a more dynamic and competitive European industry, promotion of Pan-European mobility of researchers are implemented by co-financing transnational access to research infrastructures and joint research activities through Research and Innovation and Coordination and Support Actions' funding schemes. Establishment by the research community of European technology platforms are being capitalised. Mapping of research infrastructures and E\&T capabilities is allowing a closer cooperation within the European Union and beyond, benefiting from multilateral international agreements and from closer cooperation between Euratom, OECD/NEA, IAEA and international fora. 'Euratom success stories' in facilitating Pan-European E\&T collaborative efforts through Research and Training framework programmes show the benefits of research efforts in key fields, of building an effective 'critical mass' and implementing European MSc curricula, of promoting the creation of 'Centre of Excellence' with an increased support for 'Open access to key research infrastructures', exploitation of research results, management of knowledge, dissemination and sharing of learning outcomes.
\end{abstract}

\section{Introduction to the European landscape}

Nuclear power plants (NPP) currently provide $30 \%$ of the overall European electricity generated and $15 \%$ of the primary energy consumed in the European Union. In 2016, 126 NPPs are in operation in Europe, representing a total installed electrical capacity of $137 \mathrm{GWe}$ and a gross electricity generation of around $850 \mathrm{TWh}$ per year. Nuclear fission is a major contributor already today as a low-carbon technology in the Energy Union's strategy to reduce its fossil fuel dependency and to fulfil its 2020/2030/2050/ COP21 energy and climate policy objectives [1]; however, the sector is currently facing several challenges: (a) one concerns the plans of most EU Member States (MS) to extend the design lifetime of their nuclear power plants; (b) other countries, such as France, Finland, Czech Republic, Hungary and the UK, are planning new builds; (c) while others, like Germany, are either considering or have excluded nuclear energy from their energy mix for now; (d) a bigger share of renewables should be fostered at European level; and (e) fierce international competition is

\footnotetext{
* e-mail: roger.garbil@ec.europa.eu
}

taking place on a global level. Interest in nuclear power is boosted by the need to ensure a secure and competitive supply of energy and by concern over climate change. Finally, whether or not Member States will continue to use nuclear for their electricity production, for both energy and non-energy applications, Europe will need to keep and train highly qualified staff across the whole continent and share its knowledge worldwide.

\section{Euratom Treaty and EU/Euratom legislative framework [2]}

The Euratom Treaty provides the legal Framework to ensure a safe and sustainable use of peaceful nuclear energy across Europe and help non-EU countries meet equally high standards of safety and radiation protection, safeguards and security. With legally binding Nuclear Safety Directive (2009/71/Euratom) and its latest amendment (2014/87/Euratom), EU nuclear stress tests, including safety requirements of the Western European Nuclear Regulators Association (WENRA) and the International Atomic Energy Agency (IAEA), the EU became the first major regional nuclear actor with a legally binding 
regulatory framework as regards to nuclear safety. Furthermore, this legal framework has been recently complemented by the Directive (2011/70/Euratom) that establishes a Community framework for the responsible and safe management of spent fuel and radioactive waste (both from fission and fusion systems), and the Directive (2013/59/Euratom) laying down basic safety standards for protection against the dangers arising from exposure to ionising radiation. Directives on Nuclear Installations' Safety (Art. 7), Nuclear Waste Management (Art. 8), Basic Safety Standards (Ch. 4) and IAEA Convention on Nuclear Safety, all emphasize that each MS shall take the appropriate steps to ensure that sufficient numbers of qualified staff with appropriate education, training and re-training are available for all safety-related activities in or for each - nuclear installation throughout its life. 'Conclusions' were issued at: (a) EU Competitiveness Council in November 2008 encouraging Member States and the EC to establish a 'review of EU professional qualifications and skills' in the nuclear field; and (b) a 'Second Situation Report on EU E\&T in the Nuclear Energy Field' was published in 2014 by the European Human Resources Observatory in the Nuclear Energy Sector (EHRO-N, the latest created in 2009 by the European Nuclear Energy Forum (ENEF)).

The EC promotes and facilitates through the Euratom Framework Programmes (FP) [3] nuclear research and training activities within MS and complements them through its specific Community FP. R\&D activities supporting the enhancement of the highest nuclear safety standards in Europe are mainly promoted by EC DG RTD indirect actions together with JRC direct actions. JRC has also been providing for 30 years internationally recognized scientific and technical support e.g. training courses, educational modules, support to the European Safeguards R\&D Association (ESARDA), and CBRN risk areas of chemical, biological, radiological and nuclear. European and International safeguards authorities such as Euratom, MS and IAEA benefitted from JRC's dedicated R\&D and operational support in collaboration with other EC DGs, ENER, TRADE, DEVCO and EEAS [4]. Beyond EU borders, DEVCO manages the 'Instrument for Stability (IfS)' and the 'Instrument for Nuclear Safety Cooperation (INSC)' where among others an initiative on Training and Tutoring (T\&T) provided post graduate professional education to expert staff at Nuclear Regulatory Authorities (NRA) and Technical Support Organizations (TSO), both in terms of management and of technical means in the areas of nuclear safety and radiation protection which proved to be very successful in strengthening local organizations and regional cooperation.

\section{EU/Euratom initiatives are being capitalised}

The European Commission helps to stimulate joint funding from Member States and/or enterprises, and benefits are being capitalised from the increasing interaction between European Technology Platforms (ETPs) [5] launched during the 7th Framework Programme (2007-2013), namely, the 'Sustainable Nuclear Energy Technology Platform' (SNETP incorporating NUGENIA Generation II III water cooled reactor technology, ESNII Generation IV fast reactors aiming at closing fuel cycle, and NC2I Cogeneration of electricity and heat), the 'Implementing Geological Disposal of Radioactive Waste Technology Platform' (IGDTP), the 'Multidisciplinary European Low Dose Initiative' (MELODI association), the European Energy Research Alliance (EERA) Joint Programme in Nuclear Materials (JPNM), the Strategic Energy Technology Plan (SET-Plan) [6] and other EU stakeholders (ENEF, ENSREG, WENRA, ETSON, FORATOM, etc.) [7] as well as OECD/NEA, GIF and IAEA at international level [8].

Euratom Fission Training Scheme (EFTS) coordination actions aimed at structuring Higher University Education Master of Science (MSc) training and career development benefitting from a European Credit Transfer and Accumulation System (ECTS) initiated by the Bologna Process in 1999 for higher academic education. European Credit System for Vocational Education and Training (ECVET) launched in Copenhagen in 2002 is also promoted today for lifelong learning in the field of nuclear and successfully tested across a wide range of industrial sectors. It is further promoting transparency, mutual trust, continuous professional development based on a modular course approach and recognition of learning outcomes that refer not only to knowledge but also to management of skills and competences [9].

Successful Euratom EFTS - selected on a competitive basis and promoted through the scientific community (detailed information on all projects is available on CORDIS [10]) - covered highly relevant E\&T needs for industry (energy and non-energy including medical) and associated end users: ECNET (2011-2013), EU-China nuclear cooperation; ENEN-III (2009-2013), Generation III and IV engineering training schemes for nuclear systems suppliers and engineering companies; TRASNUSAFE (2010-2014) nuclear safety culture in health physics (e.g. ALARA principle applied to both industrial and medical fields); CORONA-II (2015-2018) on the creation of a regional centre of competence for VVER technology and nuclear applications; CINCH-II (20132016) cooperation establishing a European MSc in nuclear and radiochemistry; EUTEMPE-RX (2013-2016) for Medical Physics Experts in Radiology and focusing on the implementation of the BSS Directive; GENTLE (2013-2016) delivering graduate and executive nuclear training and lifelong education with a focus on synergies between industry and academia; NUSHARE (2013-2016) on nuclear safety culture competences for policy makers, regulatory authorities and industry; PETRUS III (20132015) a program for a European RadWaste MSc, E\&T research on underground storage addressing mainly radiation waste management agencies; ENEN-RU-II (2014-2017), ETKM MSc cooperation with Russia, ROSATOM and MEPhi and VVER technology; and ENETRAP-III (2014-2018) MSc in radiological protection addressing mainly nuclear regulatory authorities and TSOs. Some of the above EFTS are developing European Passport (Europass) based on personal transcripts of 
records and learning outcomes modules obtained through various paths (traditional face-to-face, virtual classroom, training and tutoring, internships, workshops, webinars, online or blended learning tools such as e-learning or today's Massive Open Online Courses (MOOC)). IT technologies are being set to transform today the higher education system, benefitting from the huge capabilities of computer simulations and virtual reality accessible anywhere and at any time, however it will never constitute per se a license of a practice or an official authorization to operate or to supervise nuclear facilities from national nuclear regulatory authorities but complementary IT tools benefits for E\&T and KSC management have to be acknowledged.

Support from Euratom to key research infrastructures has proven to be highly beneficial to the scientific community at facilitating Pan-European mobility of researchers, engineers or scientists, transnational access to large and unique infrastructures, promoting joint research activities and collaborative efforts across a broad range of nuclear science and technologies in most fields covered by Euratom is supporting today's Euratom portfolio of success stories. Increased cooperation in research in Europe is benefitting from H2020 crosscutting support from all EU financial instruments available: ERASMUS + education and training actions (MSc, Engineers, Bachelors, Lifelong learning funding schemes across the globe), Marie Slodowska Curie Fellowships (PhDs), European Research Council on 'Excellent Science' (ERC), Fusion and ITER, JRC ETKM support using its world class laboratories, and the European Institute of Technology Knowledge Innovation Centre (EIT KIC InnoEnergy). The latest promoted a highly successful European Master in Innovation in Nuclear Energy (EMINE) involving major industrial partners AREVA, EDF, ENDESA and VATTENFALL, but also CEA (FR) and universities KTH (SE), University of Catalonia (UPC, ES), INP (Grenoble, FR) and Paris-Saclay (FR) [11].

A publication from EHRO-N in 2012 'Putting into Perspective the Supply of and Demand for Nuclear Experts by 2020 within the EU-27 Nuclear Energy Sector' [12] also confirmed today's EU challenging gap in covering $50 \%$ of nuclear experts training needs by 2020 (estimated at around 2000 a year) due to retirement by then. Faced with the challenge of shortages of skilled professionals, the nuclear fission community has called for a steady upgrade of the level of knowledge, skills and competences while striving to attract a new generation of experts to cover the entire life cycle of new nuclear power plants from design and construction to dismantling and green field. The European Union is urged to speed up implementation of EU Directives emphasizing that each MS (governments together with professional organisations and universities ensuring any adequacy between competences needed and jobs available) shall take the appropriate steps to ensure that sufficient numbers of qualified staff with appropriate education, training and re-training are available for all safetyrelated activities in - or for each - nuclear installation throughout its life.

\section{$4 \mathrm{EU} /$ Euratom E\&T in support to sustainable Fast Reactor and closed fuel cycle technologies: from technological workshops and international schools to EU training Centers of Excellence}

The OECD/NEA Generation-IV International Forum (GIF) [13] has stimulated innovation towards sustainable nuclear reactor technologies since the year 2001 such as Sodium-cooled Fast Reactor (SFR), Lead-cooled Fast Reactor (LFR), Very High-Temperature Reactor (VHTR), Gas-Cooled Fast Reactor (GFR), Supercritical Water Cooled Reactor (SCWR) and Molten Salt Reactor (MSR). On the basis of an EU Commission Decision, EU/Euratom acceded to GIF by signing in July 2003 the 'Charter of the Generation IV Forum' and the International 'Framework Agreement' existing between all Members of the Generation IV International Forum. The Joint Research Centre (JRC) of the European Commission is the Implementing Agent for EU/Euratom within GIF. In November 2016, EU Commissioner T. Navracsics has signed on behalf of EU/ Euratom the agreement to extend, for another ten years, the Framework Agreement for an International Cooperation on Research and Development of Generation IV Nuclear Energy Systems. EU/Euratom contributions shall also be extended towards all respective six GIF Systems Arrangements as Fast Neutron Reactor systems are considered as key for the deployment of sustainable nuclear fission energy. EU/Euratom framework programmes constantly promote research and training, innovation and demonstration of nuclear fission technologies to achieve EU SET-Plan objectives, by 2020, being: (1) to maintain the safety and competitiveness in fission technology, and (2) to provide long-term waste management solutions; and by 2050, (3) to complete the demonstration of a new generation (Gen-IV) of fission reactors with increased sustainability, namely, via the European Sustainable Nuclear Fission Industrial Initiative (ESNII), and (4) to enlarge nuclear fission applications beyond electricity production through the Nuclear Cogeneration Industrial Initiative (NC2I).

The European Commission has also promoted since 2007 the establishment of technology platforms such as the Sustainable Nuclear Energy Technology Platform (SNETP) gathering today around 100 key stakeholders mainly from research organisations, industry and academia. Its latest 2013 Strategic Research and Innovation Agenda (SRiA) and 2015 Deployment Strategy gave prioritization between all GIF systems to the three most advanced systems. Sodium Fast Reactor (SFR) is the reference technology since it already has substantial technological and operations feedback in Europe and today's French ASTRID demonstrator lead by CEA is promoted. Lead Fast Reactor (LFR) technology has significantly extended its technological base. It can be considered as the short term alternative technology with support first from MYRRHA (Multi-purpose hYbrid Research Reactor at SCK CEN (BE), even the leading ESNII industrial demonstration project following the French government's decision to delay the construction 
of ASTRID, a Pb-Bi Accelerator Driven System) and later ALFRED projects. Gas Fast Reactor (GFR) technology is considered to be a long-term alternative option and ALLEGRO is supported by the Visegrad 4 central European countries (CZ, SK, HU and PL). With innovative emerging technologies fostering increased efficiency, competitiveness and enhanced safety through design, one could expect: (a) by 2025, a licensed SMR and/or cogeneration (V)HTR design(s) available in the EU, with operating demonstrator(s) by 2030; and (b) by 2030, at least one Gen-IV demonstrator fast reactor in Europe, including associated fuel cycle facilities.

Gen-IV innovative nuclear reactors are very attractive to young students, scientists and engineers engaging in a nuclear career, thanks to the related scientific challenges characterized by higher operating temperatures, studies on high temperature materials, corrosion effects, heavy liquid metal thermodynamics, innovative heat exchangers, fast neutron fluxes for both breeding and enhanced burning of long-lived wastes [14]. Development, fabrication and testing of entirely new nuclear fuels, advanced fuel cycles, fuel recycling concepts, including partitioning and transmutation, are required, all promoting excellent topical opportunities for internships or $\mathrm{PhD}$ studies within $\mathrm{R} \& \mathrm{D}$ laboratories. Beyond the obvious educational merit for young engineers investing on average into additional two years' fast reactor studies, scientists and engineers would also have a broader expertise when working on enhanced LWR technology and cross-cutting safety, core physics, engineering and materials areas. Also, a successful Gen-IV design team would highly benefit from 'systemic' and 'interdisciplinary' specialists in the various scientific disciplines involved such as neutronics, thermal-hydraulics, materials science, coolant technologies together with 'assembling' engineers capable to perform optimized integrations of all topical results into 'realistic' reactor components and 'most efficient' balance of plants.

Successful EU/Euratom projects - selected on a competitive basis and promoted through the scientific community (detailed information on all projects is available on CORDIS) - covered highly relevant E\&T needs for research organisations, industry and associated end users. EU/Euratom fission work programmes supported 'GIF concept-oriented' projects, in line with the strategy implemented by the European Commission together with EU leading Member States, but also key cross-cutting fields of nuclear safety, fuel developments, thermal hydraulics, materials research, numerical simulation, design activities of future reactor technologies, partitioning and transmutation, support to infrastructures, education, training and knowledge management, and international cooperation. EU/Euratom framework programmes consistently co-funded dedicated collaborative 'Research and Innovation' (E\&T evaluated at around $5 \%$ of the total budget for each projects) and 'Coordination and Support Actions' (E\&T could be up to $100 \%$ of the total budget for each projects) in the area of advanced nuclear systems. All R\&D projects incorporated E\&T tasks, workshops focused on R\&D progress but also training courses for Higher University MSc and $\mathrm{PhD}$ students co-organised in collaboration with industrial and research laboratories. They are usually open to participants from partner institutions outside the project and third countries. Coordination support from ENEN is systematically provided to strengthen its international visibility and ensure the highest impact of dissemination and sharing of knowledge among the European scientific community.

Some projects were 'concept oriented' such as: CPESFR (2009-2013) Collaborative Project on European Sodium Fast Reactor; LEADER (2010-2013) Lead-cooled European Advanced Demonstration Reactor; HELIMNET (2010-2012) Heavy liquid metal network; GOFASTR (2010-2013) European Gas Cooled Fast Reactor; VINCO (2015-2018) Visegrad Initiative for Nuclear Cooperation; ESNII + (2013-2017) Preparing ESNII for HORIZON 2020; EVOL (2010-2013) Evaluation and Viability of Liquid Fuel Fast Reactor System; SAMOFAR (2015-2019) A Paradigm Shift in Reactor Safety with the Molten Salt Fast Reactor, MYRTE (2015-2019) MYRRHA Research and Transmutation Endeavour and ESFR-SMART (20172021) European Sodium Fast Reactor Safety Measures Assessment and Research Tools.

Other projects addressed cross-cutting research and innovation areas such as: GETMAT (2008-2013) Gen-IV and Transmutation MATerials; MATTER (2011-2014) MATerials TEsting and Rules; MATISSE (2013-2017) Materials' Innovations for a Safe and Sustainable nuclear in Europe; FAIRFUELS (2009-2015) FAbrication, Irradiation and Reprocessing of FUELS and targets for transmutation; F BRIDGE (2008-2012) Basic Research for Innovative Fuels Design for GEN IV systems; THINS (2010-2015) Thermal-hydraulics of Innovative Nuclear Systems; SEARCH (2011-2015) Safe ExploitAtion Related CHemistry for HLM reactors; SESAME (2015-2019) Thermal hydraulics Simulations and Experiments for the Safety Assessment of MEtal cooled reactors; SACSESS (2013-2016) Safety of ACtinide Separation processes; GENIORS (2017-2021) GEN-IV Integrated Oxide fuels recycling strategies; CINCH-II (2-13-16) Cooperation in education and training In Nuclear Chemistry; ASGARD (2012-2016) Advanced fuelS for Generation IV reActors: Reprocessing and Dissolution; TALISMAN (2013-2016) Transnational Access to Large Infrastructure for a Safe Management of ActiNide; ARCAS (2010-2013) ADS and fast Reactor CompArison Study in support of Strategic Research Agenda of SNETP; JASMIN (2012-2016) Joint Advanced Severe accidents Modelling and Integration for Na-cooled fast neutron reactors; and SARGEN-IV (20122013) Towards a harmonized European methodology for the safety assessment of innovative reactors with fast neutron spectrum planned to be built in Europe.

As an illustration of the consideration brought to E\&T in the abovementioned projects, E\&T activities within FP7 CP-ESFR included five European Sessions dedicated to SFR and have been organized by the ESML (Ecole du Sodium et des Métaux Liquides) at CEA-Cadarache in France, University of 'La Sapienza' (IT), Karlsruhe Institute of Technology (KIT, DE) and the University of Madrid (ES). More than 120 trainees and PhD students were welcomed during these five sessions. Within the following H2020 project ESNII+, a large effort dedicated to 
Fast Neutron Reactors cooled by sodium, lead and gas has been foreseen. Eight seminars and two summer schools are being organized between 2014 and 2017 and dedicated to various topics such as: (a) fuel properties and fuel transient tests; (b) core neutronic safety issues; (c) instrumentation for fast neutron reactors; (d) thermal-hydraulics and thermo-mechanical issues; e) mitigation of seismic risks; (e) coolant physico-chemistry and dosimetry, and quality control strategy; (f) safety assessment of Fast Neutrons reactors; (g) severe accidents in Fast Neutron Reactors; and (h) sitting and licensing of Fast Neutron reactors.

One should also highlight the FP7 ENEN-III project which has elaborated training schemes for the development and pre-conceptual design of Gen-IV nuclear reactors. All six Gen-IV reactor types were considered; however, emphasis has been given on the three concepts (SFR, LFR and GFR) prioritized within the EU/Euratom framework. Gen-IV training schemes are more research oriented and they have a broader scope than Gen II III training schemes. Following basic principles and introductory courses common to all Gen-IV concepts, dedicated schemes for experts and using supporting research facilities have been identified, and learning outcomes classified accordingly.

To ensure any continuity between implementation of such FP7 ENEN-III training schemes, organizing EU/ Euratom projects workshops on R\&D progress and international schools could be challenging if they would be exclusively supported by Euratom due to a risk of a lack of continuity between projects selected on a competitive basis following yearly of bi-annual call for proposals. Euratom is highly recognized as a framework benefitting from a high European added value fostering increased cooperation and joint programming activities between EU and Member States, Public and Private investments involving industry, research centres, academia and technical safety organisations capitalizing international partnerships and any use of key infrastructures.

EU/Euratom Education, Training, Skills and Competences sustainable objectives are fulfilled as national and European 'Technological schools' are today evolving successfully towards 'International training platforms' (or Centers of Excellence) [15,16] e.g. in France, Belgium, Germany, Italy, Sweden or the UK. Courses and training schemes further benefit from a consolidated pedagogical support, a database of lecturers, a management of course materials with a certified Quality Assurance process including evaluation procedures, regular updates and better harmonisation, communication and logistical organization, and an increasing mutual international recognition of certificates or diploma. The availability of attractive research infrastructures in support to education, training, skills and competences has to be underlined as they highly contribute to quality hands-on training in nuclear technology such as research reactors, critical assemblies, thermal-hydraulic facilities, fuel cycle-related laboratories and hot-cells, computer-based simulators and state-of-theart computer codes.

As an illustration where EU/Euratom projects have contributed in a relevant way other the years by supporting dedicated E\&T activities, France is providing an important nuclear teaching platform organized around engineering schools, universities, research laboratories, technical schools but also nuclear companies or dedicated entities for professional training. Within this context, the Institut National des Sciences et Technologies Nucléaires (INSTN), with its own Nuclear Engineering Master level (or specialization) degree and a catalogue of more than 200 vocational training courses, is a major nuclear E\&T operator in Europe. The International Institute for Nuclear Energy (I2EN) launched in 2010 is federating French entities delivering high level curricula in nuclear engineering and science and is promoting the French offer for education and training in partner countries. With the objective to build ASTRID in France, an important and a rapid increase of $\mathrm{R} \& \mathrm{D}$ work orientated towards the design and conceptual evaluations has taken place. Two reactors are currently being dismantled namely PHENIX and SUPERPHENIX, and it was therefore necessary to further support E\&T initiatives delivered at the Ecole du Sodium et des Métaux Liquides (ESML). The Ecole des Combustibles (EC) is also located in CEA Cadarache with the support of INSTN for the development of SFR technology. Trainees usually belonged to French companies such as CEA, EDF, AREVA, IRSN, or any companies involved in sodium activities and belonging (or not) to the nuclear industry. Specific training sessions were also provided to German operators (1983), Japanese operators for the first start-up of the Monju reactor (1990) or in support to PFR and DFR decommissioning projects (UK). Specific sessions were provided to the chemical industry such as UOP (USA). And more recently, ESML in association with the plant operator from PHENIX has extensively increased its offer to foreign institutes such as trainees from CIAE in China, ROSATOM in Russia on Reactor technologies, safety and operation, or IGCAR in India dedicated to Safety. The pedagogical approach consists of combining lectures, discussions and hands-on training on Sodium loops. Since 1975, more than 5000 trainees benefitted from training at the Sodium School.

In Belgium, SCK•CEN Academy for Nuclear Science and Technology was established at the beginning of 2012 benefitting from sixty years of research into peaceful applications of nuclear science and technology, material and fuel research performed today at the BR2 reactor. With such an extensive experience and involvement in the development of an innovative Multi-purpose hYbrid Research Reactor for High-tech Applications (MYRRHA), major nuclear installations and specialist laboratories are available today on site, $\mathrm{SCK} \bullet \mathrm{CEN}$ is well placed to take on the role of an international education and training platform on Heavy Liquid Metal (Pb-Bi). In addition, IAEA and SCK•CEN Academy have agreed in 2015, CEA-INSTN and SCK•CEN have also signed in September 2016 cooperation framework agreements on E\&T.

EU/Euratom Education and Training initiatives are increasingly being organized with the support of the European Commission to the European Nuclear Education Network (ENEN), and within the frame of projects cofunded through the Euratom Framework Programmes. ENEN was established in 2003 as a French non-profit association to preserve and further develop expertise in the 
nuclear fields through Higher Education and Training. ENEN has currently over 60 members, mainly in Europe but also from Japan, Russia, South Africa, Canada, Ukraine including strengthen cooperation with IAEA. This objective is realized through the co-operation between universities, research organizations, regulatory bodies, the industry and any other organizations involved in the application of nuclear science and radiation protection and by fostering students' mobility schemes within Europe and beyond. National and international organizations currently undertaking E\&T activities in support to Fast Reactor and closed fuel cycle technologies are all very keen to cooperate and to share their resources, to open key research infrastructures in support to common challenging initiatives to the highest benefit of the entire nuclear community (IAEA initiative on the creation of International Centers of Excellence on Research Reactors (ICERR) is very welcoming), supporting international mobility of young scientists or researchers and mutual recognition of competences, giving overall a new impetus, high incentives and perspectives for E\&T within Europe and beyond.

\section{EU/Euratom research perspectives and outreach}

The 'Euratom experience' with the Framework Programmes has been a consistent success in pursuing excellence in research and facilitating pan-European collaborative efforts across a broad range of nuclear science and technologies, including nuclear safety, safeguards and security within EU and non-EU countries. Associated education and training activities are in line with Horizon 2020's key priorities, but also in the proposal of Horizon Europe (2021-2027), excellent science, industrial leadership, and societal challenges, one of the latter being the secure, clean and competitive energy challenge for Europe in the context of the Energy Union.

Nuclear 'Research and Innovation and Demonstration' needs a policy-driven programmatic approach, to meet the strategic objectives of EU 2020/2030/2050/COP21 Energy and Climate policies. Lack of coordinated research leads to national or bilateral programmes in countries with large capabilities, threatening smaller countries with scientific isolation and loss of expertise. In nuclear medical applications, proliferation vigilance and waste management, non-participating countries risk to become second class.

In contrast to earlier approaches characterised by a bottom-up projects' selection on a competitive basis and their following implementation, future nuclear $\mathrm{R} \& \mathrm{D}$ should be policy driven. A programmatic approach involving all relevant stakeholders and fora at an early stage - rather than a project approach - should be called for, to meet the strategic objectives of EU energy and climate policies: sustainability, security of supply and competitiveness for a future low-carbon economy. EU energy R\&D should satisfy all three policy pillars simultaneously, in a coordinated and output-oriented manner. This type of structured R\&D organisation should nevertheless not exclude some funding being reserved for good ideas by small research groups (technology watch), since creative solutions often emerge from unexpected initiatives.

National laws and EU Directives should play a bigger role in the organisation of research and training (typically through a roadmap, deployment strategies and priorities), with national organisations (e.g. for nuclear waste management, with the launch of a European Joint Programme EURAD in June 2019) taking the lead in $\mathrm{R} \& \mathrm{D}$ programmes which should be coordinated at the EU level.

It seems appropriate to use different partnerships for collaboration depending on the subjects treated. Publicpublic partnerships between the European Commission and EU Members States remain crucial to long term R\&D (especially infrastructures, demonstration and prototype plants, and basic nuclear education, training, skills and competences) and to societal R\&D (such as external costs and radiation protection). In contrast, public-private partnerships are more appropriate for short-term work (design and operation of reactors and waste facilities, regulation, procedures and practical training). For management and operation of large infrastructures of common interest, legal schemes such as a joint technological initiative or European research consortiums should be considered. In addition, use of all H2020 funding instruments available should be capitalised together with the KIC InnoEnergy of the EU's European Institute of Innovation and Technology, and where needed, of EU structural funds in combination with H2020.

The attractive and challenging scientific topics associated with innovative and sustainable Fast Neutron Reactors create a new and highly incentive context for students and young scientists with high potential to embark on a nuclear career. The perspective of new build, innovative Small and Modular Reactors (SMR), construction of SFR, LFR or GFR demonstration reactors or prototypes are key drivers. EU/Euratom education, training, skills and competences sustainable objectives are fulfilled as national and European 'Technological schools' are today evolving successfully towards 'International training platforms' (or Centers of Excellence). An exemplary and precursory approach in France has allowed a preservation of knowledge on SFR and know-how gained during the past four decades. INSTN, I2EN, SCK•CEN and ENEN are among others, respectively, increasingly capitalising the practical and sustainable implementation of training schemes, any complementary skills and competences in addition to knowledge, for the qualification and mobility of workers, scientists and engineers. Promoting any further use of key experimental infrastructures, research reactors, irradiation facilities and hot laboratories, simulation platforms and computer codes are highly valuable, and a long-term investment supporting international cooperation.

The dynamic and fast-evolving nuclear industry and its research activities need to be supported by an up-to-date education and training system based on mutual trust, on a certified quality assurance process, on transparency and integration of pan European needs that will deliver an increased number of highly skilled and trained personnel. 
This updated system could be based on the combination of traditional learning paths and, innovative ones, such as virtual classrooms and MOOCs, to be most effective. All EU stakeholders, from policy-makers, academia, research organisations, regulators, and industry are unanimous in stating that 'a common pan European approach is the way forward', benefitting from EFTS, ECTS and ECVET in combination to 'Open Access to key or world class infrastructures'. For the funding of education and training, beyond the usual programmes in schools and universities, creative instruments could be envisaged. For example, should the minimal educational and training be better specified within national law or by a Euratom Directive? Also, it could maybe be reasonable to set up a common education and training fund jointly managed by the European Commission and Member States and, similarly to the funds for waste management, financed by a mandatory levy on nuclear generators based on nuclear MWh produced if we wish to ensure the meeting of all challenging targets.

\section{References}

1. European Energy Strategy: Secure, competitive, and sustainable energy. http://ec.europa.eu/energy/en/topics/ener gy-strategy

2. EU/Euratom legislative framework. http://ec.europa.eu/ energy/en/topics/nuclear-energy

3. Horizon 2020 European Research Framework Programme. http://ec.europa.eu/research/horizon2020/index en.cfm; http://ec.europa.eu/programmes/horizon2020/h2020-sections

4. European Commission Departments (Directorates-General) and services. http://ec.europa.eu/about/ds en.htm

5. European Technology Platforms (ETPs). http://cordis. europa.eu/technology-platforms/; SNETP Sustainable Nuclear Energy Technology Platform. http://www.snetp.eu/; IGDTP Implementing Geological Disposal of Radioactive Waste. http://www.igdtp.eu/; MELODI Multi-disciplinary European Low Dose Initiative. http://www.melodi-online.eu/

6. Strategic Energy Technology Plan (SET-Plan). http://ec. europa.eu/energy/technology/set plan/set plan en.htm

7. Independent authoritative expert body with regulatory backgrounds for the stress tests ENSREG European Nuclear Safety Regulator Group. http://ec.europa.eu/energy/nuclear/ ensreg/ensreg en.htm; ENEF European Nuclear Forum Energy. http://ec.europa.eu/energy/nuclear/forum/forum en.htm

8. OECD/NEA Nuclear Energy Agency. http://www.oecdnea.org/; GIF Generation-IV International Forum. http:/ www.gen-4.org/; IAEA International Atomic Energy Agency. http://www.iaea.org/

[9]. Bologna Process in 1999. http://ec.europa.eu/education/ policies/educ/bologna/bologna_en.html; Copenhagen Declaration in 2002. http://ec.europa.eu/education/lifelonglearning-policy/ecvet_en.htm; ECVET European Credit System for Vocational Education and Training. http:// www.ecvet-team.eu/

10. CORDIS, European Community Research and Development Information Service. http://cordis.europa.eu/home_en. html; EU Participant Portal. http://ec.europa.eu/re search/participants/portal/desktop/en/home.html

11. EIT KIC InnoEnergy MSc EMINE - European Master in Nuclear Energy. http://www.innoenergy.com/education/ master-school/msc-emine-european-master-in-nuclear-energy/

12. EHRO-N, European Human Resources Observatory for the Nuclear sector, Perspective report. http://ehron.jrc.ec.euro pa.eu/sites/ehron/files/documents/public/ehro-n_putting into_perspective_report_2012_05_25_0.pdf

13. GIF Generation- $\overline{\mathrm{I} V}$ International $\overline{\text { Forum Progress }} 2015$ in Nuclear Energy, vol. 77. http://www.sciencedirect.com/ science/journal/01491970/77; GIF Annual reports. https://www.gen-4.org/gif/jcms/c 44720/annual-reports

14. F. Roelofs, Ed., Thermal Hydraulics Aspects of Liquid Metal Cooled Nuclear Reactors, 1st edn. (Elsevier, 2018), ISBN: 9780081019801, https://www.elsevier.com/books/thermalhydraulics-aspects-of-liquid-metal-cooled-nuclear-reactors / roelofs /978-0-08-101980-1

15. INSTN, Institut National des Sciences et Technologies Nucléaires. http://www-instn.cea.fr; I2EN, the International Institute for Nuclear Energy. http://www.i2en.fr; SCK $\bullet$ CEN Academy for Nuclear Science and Technology. http://www.sckcen.be/en/Education_training/SCKCEN academy; ENEN European Nuclear Education Network Association. http://www.enen-assoc.org

16. FR13 Conference Proceedings held in Paris, France, from 4 to 7 March 2013. http://www-pub.iaea.org/books/IAEA Books/10682/Fast-Reactors-and-Related-Fuel-Cycles-SafeTechnologies-and-Sustainable-Scenarios-FR13-Proceedingsof-an-International-Conference-on-Fast-Reactors-and-Relat ed-Fuel-Cycles-Paris-France-4-7-March-2013

Cite this article as: Roger Garbil, Euratom success stories in facilitating pan-European education and training collaborative efforts, EPJ Nuclear Sci. Technol. 6, 46 (2020) 